\title{
Competitive intelligence lessons Hurricane Katrina can teach: what are intelligence failings and how they can be overcome?
}

\author{
Marié-Luce Muller \\ Director, IBIS \\ mlm@ibis.co.za \\ www.ibis.co.za \\ Zenita Dürrheim \\ Research Analyst \\ zd@ibis.co.za \\ www.ibis.co.za
}

The recent tragic events unfolding after Hurricane Katrina hit the US east coast has once again raised thoughts about and debate around the value of early warning and, in particular, what happens when one has early warning or intelligence of an impending threat or opportunity and then does nothing with that warning. Why does it seem as if the decision makers in the US were totally unprepared for the magnitude of the disaster? Was there ample warning that was not heeded? Can one learn from other events such as the December 2004 tsunami and the events of 11 September 2001? Will Hurricane Katrina take a prominent position in the history of intelligence failures? This article will attempt to answer that question.

Katrina's devastation might be hard to comprehend but it was not unexpected. Major disaster areas were declared and emergency supplies were ready because there was ample warning of the ferocity of this hurricane. But, the top leadership in the US seemed unprepared for the looming domestic crisis. It took two days for Bush to fly over the disaster zone in Air Force One, and four days for him to touch down (Newsweek 2005).

Hurricane Katrina is not the first and will certainly not be the last event to uncover the shortcomings of forewarning. By analysing what went wrong or what the shortcomings were, some lessons can be formulated that can also apply to companies. Incidentally, corporate life is full of examples of intelligence failings. Johnson (2002) mentions everyday examples of less than accurate corporate forecasting, for example the dot-com meltdown and performance estimates. Johnson (2002) asks how often has one read of 'below analysts' expectations'.

Wergeles (2005) argues that there is seldom a lack of indicators that precede surprising events and asks the following questions:

Could these events have been predicted before they occurred? How can information collection and reporting capabilities be improved that would allow us to forecast these types of events sooner in the future? 
In addition one could ask: With all the predictions, information and reporting capabilities intact and with accurate forecasting, does this ensure that the right strategic decisions and planning will take place? BBC News Online world affairs correspondent, Paul Reynolds (Reynolds 2004) took the intelligence failures over Iraq and summarized the factors that led to intelligence failures. One could take these factors and apply them to the Katrina case and also to our own corporate realities.

- Overestimation. 'This is characterised by a determination to overemphasise information, leading to a false conclusion' (Reynolds 2004). Often this is to impress the decision maker by sensationalizing events. From a decision maker's point of view, it is also true that they often do not heed warnings and bad news and are reluctant to accept intelligence that contradicts a current intelligence picture.

- Underestimation. 'This is the syndrome in which the intelligence services or the political leadership completely misread the enemy's intentions' (Reynolds 2004).

First impressions can be misleading. On Katrina, officials at first reported that the old downtown of New Orleans had been spared the worst. But as levees and pumps failed, the area was flooded and the magnitude of the devastation there, and elsewhere along the Gulf Coast, eclipsed initial assessments and highlighted the glaring shortcomings in contingency plans.

Underestimation and overconfidence are closely linked. Of course overconfidence often leads to complacency, the next cause of failure.

- Complacency. 'This happens when you know the enemy might do something, though you are not sure what or when, and yet you do nothing anyway' (Reynolds 2004).

Preventive maintenance matters. New Orleans's failure to keep levees and pumps in prime condition is at least partly to blame for the flooding. In the corporate world, this is a regular occurrence - in particular, larger companies start thinking they are invincible, ignoring indicators of potential threats and are often surprised. Enron's leaders, for example, thought they were untouchable and that their power and high government connections made them invincible.

- Ignorance. When there is virtually no intelligence, you are at the mercy of events. But even the most obscure events leave indicators or signs in the phase running up to the event. These are not normally clearly visible and also need to be integrated into a larger picture to interpret their meaning. It could also be a case of not seeing what you see and then failing to anticipate the impact an event could have.

Internal documents show the government's disaster chief waited roughly five hours after Hurricane Katrina struck the Gulf Coast before asking Homeland Security Secretary Michael Chertoff to dispatch 1000 agency employees to the region. The documents show the volunteers were given two days to arrive (WSBTV 2005).

- Failure to join the dots. This is failing to make connections between bits of intelligence to make a coherent whole - this analysis and interpretation is the core function of competitive intelligence (CI).

These dots can be few and far between, seemingly unrelated and residing in various sources of information (Reynolds 2004). Connecting these dots and interpreting their meaning and impact ultimately requires human input. In the 
September 11 case, intelligence workers were unable to analyse the signals they received from the field. They lacked the ability to integrate and synthesize the information they were already receiving and to make sense of it rather than lacking the analytical models and frameworks (Johnson 2004). Often analysts are out to impress rather than just putting the various pieces together, making up the bigger picture and conveying the core message in a simple, understandable manner.

Taking a corporate example of such signs and indicators, Wergeles (2005) mentions a few key signals when a competitor plans to launch a new product:

- Hiring or contracting for additional personnel to develop, market and sell the product

- Improving or expanding the production facility to handle the increased product load

- Writing an advertorial and preparing marketing material

- Applying for new product trademarks

- Applying for changes in the municipal regulations to allow the company to expand its current facility or build a new one.

- Not seeing the bigger picture. Holtzman (2005) states that information should be integrated in a manner that allows one to see 'both the trees and the strategic forest'. The larger the competitive environment one has to track and scan for competitive threats and opportunities, the more daunting the task - and perhaps there comes a point where intelligence failures should not come as a surprise. Does it not sometimes become an impossibility?

Intelligence capabilities of companies and countries alike, although holding potentially high strategic value, do have limitations and foremost among these is a lack of long-term, holistic focus leading to an ability to see threats and opportunities. Of course, the further into the future one sees, the less accurate the competitive picture could become.

- False intelligence and a failure to verify information and sources of information.Newsweek (2005) reported on the intelligence used in Colin Powell's speech to the UN in 2003 spelling out the case for war against Iraq. It has become known that the speech, and thus the case for war, rested on a single piece of information from a highly unreliable source and that warning of the lack of integrity of the information was given. An Iraqi defector, code named 'Curve Ball' who was ostensibly well connected but was also known to be of dubious character, was the source of that information. Despite warnings about the integrity of the information by some analysts in the CIA, decision makers soon responded by saying that there will be war regardless of what Curve Ball said or did not say. Forcing intelligence into formats that would fit the intelligence picture is the death knell of any intelligence operation whether corporate or government. It is clear that the intent to go to war was cast in stone and that no piece of information that pointed to the lack of argument to go to war, was going to sway the decision makers. Action relied on flawed intelligence and conclusions.

The afore-mentioned event underlines the danger of human intelligence. Whenever human personalities are involved, the opportunity for mistakes is enriched to the point of absurdity (Johnson 2004). The US government prefers the information provided by human sources. The value of reliable human sources should however not be underestimated especially in the corporate 
environment where sales and marketing employees are invaluable sources of market information. Human sources often report unique insights that are not available from published, secondary sources.

- Groupthink. Hampered by a 'group think' dynamic that caused them to view all Iraqi actions in the harshest possible light, US intelligence officials repeatedly embellished fragmentary and ambiguous pieces of evidence, making the danger posed by Iraq appear far more urgent than it actually was (Newsweek 2005).

When UN inspectors reported that they could not find any Iraqi weapons of mass destruction, for instance, the CIA dismissed the inspectors as being misled. Yet, dubious sources like Curve Ball, whose stories fit into the preferred assessment of the situation, were assimilated.

'Mindsets' have been a source of intelligence policy failures for decades. Strategic planners and intelligence professionals, whose effectiveness depends on overcoming mindsets, face a particular challenge when they work in a bureaucratic or hierarchical setting (Feder 2005). In CI, teams of analysts often start thinking along the same lines, reaching similar conclusions based on similar assessments.

- Making processes and structures too cumbersome. A bureaucracy is slow to respond to events, impedes intellectual and analytic initiative and diverts resources from nurturing and keeping analytic talent. Analysis typically moves slowly through the bureaucratic structure, becoming increasingly watered down along the way. Analysts must write intelligence reports for the senior levels of a government or corporate and its production takes the form of an inverted pyramid. It often starts with a junior analyst and then moves up through various layers where several changes are made and eventually it becomes a stale, broken piece of prose rather than a focused, integrated and actionable piece of intelligence (Brown Commission Report 2005).

The trouble is that lessons are not always learned, which is why the list of intelligence failures grows longer. In fact one must ask the question, how practical are those lessons? How executable are they?

\section{Ensure that CI is a company's early warning system}

Effective early warning systems have been widely recognized as worthwhile and necessary investments to avoid threats and capitalize on opportunities. Globally, there are many forms of climatic early warning systems - the latest being a device to warn against tsunamis in the aftermath of the December 2004 events in the Far East.

In January 2005, the UN launched comprehensive plans for a global early warning system to reduce the deadly toll of natural hazards, combining speedy transmission of data with training of populations at risk in a strategy that experts say could have saved scores of thousands of lives in the recent Indian Ocean tsunami (UN 2005).

In a corporate sense, early warning signals are a key foundation within a CI system and are core to building a competitive advantage as they provide a rich ground from which to draw insights into key events, changes and trends which are happening in and which are affecting the competitive market environment. The integration of intelligence with all parts of the business requires that the implications of early warning signals are understood to effectively monitor the ever-changing business environment and to provide sound advice to decision makers (Marrs and Turner 2005). 
Marrs and Turner (2005) identified a few types of early warning signals:

- Signals designed to indicate that a known type of event, opportunity or threat might occur sometime in the future. Examples would include signals designed to recognise opportunities, trends, industry changes, competitor actions/threats, economic/financial problems, new initiatives, new partnerships, strategy changes, mergers and takeovers.

In a climatic sense, it might be a case of US meteorologists detecting signs of change and if they are severe, the signs of a storm brewing. A public warning is issued about the potential danger and emergency teams can then prepare for the task ahead. In the US, the constant challenge is the quest for accurate foreknowledge. In corporates, a similar wish list exists - the need to know of events before they occur and in time to take preventive or pro-active action.

It is no longer feasible to have personnel in a busy office use a wide variety of manual notification methods, ranging from picking up a phone and calling emergency services with no automatic assurance that the messages were received or that preventive plans were rolled out (Broache 2005).

- Signals applied against future scenarios. These signals are designed to indicate whether a particular scenario is playing out. This also provides an opportunity to alter scenarios based on new or altered realities. The future is not fixed and scenarios should therefore be adapted to changing realties.

- Signals applied to key intelligence needs (KIN). These signals can be highly specific to the KIN expressed. Marrs and Turner (2005) cite responses to a new product launch as an example. How would customers and competitors respond to a new product being launched? What is a competitor's intent? If a competitor has a strategic intent, does it have the means to respond (capabilities)?

- Signals of the imminent occurrence of a new threat or event. These are the most difficult types of early warning signals. They are bits and pieces that remain out of context and meaning until someone pieces them together and makes an intuitive or experiential-based connection. Naturally these are often fraught with inaccuracies. Regarding Katrina, there were ample warnings and analyses of the impending disaster but, despite these warnings, preventive actions were not taken. In an article published by Scientific Americam.com in October 2001, Mark Fischetti wrote: 'A major hurricane could swamp New Orleans under 20 feet of water, killing thousands. Human activities along the Mississippi River have dramatically increased the risk, and now only massive reengineering of southeastern Louisiana can save the city. '

In a business context, early warning intelligence provides executives with timely, valuable information about the market and competitors that enables them to make strategic and tactical decisions more quickly. Providing senior managers with early warnings of potential opportunities and threats is one of the primary objectives of the CI practitioner. The key to being a step ahead is the ability to identify, analyse and take appropriate action on industry and competitor activities that give them a leg up on the competition.

In the case of Hurricane Katrina, perhaps the broadest lesson was the reminder that not everything is under our control. Perhaps the core lesson is still that, in the contest of nature versus man, nature at its most powerful retains the upper hand. In the corporate world, a competitive scene can change overnight and upset the competitive equilibrium. Being constantly on the lookout for threats, using CI, might prevent nasty surprises. 
In conclusion, Reynolds's (2004) intelligence example of the Trojan horse story is apt: 'The key intelligence failure was that the Trojans ignored a warning. It came from Cassandra, the daughter of Troy's King Priam. Given the gift of prophecy, she had then angered the God Apollo, who ordained that her prophecies should never be believed. So the Trojans rejected what they said was her windy nonsense. A myth perhaps, but there is a lesson to be learned.'

\section{References}

Broache, A. 2005. Weather Service launches early warning system. [Online] http://news.com.com/Weather+Service+launches+early+warning+system/2100-1038_35833442.html (Accessed 20 September 2005).

Brown Commission Report. 2005. Preparing for the 21st century: an appraisal of US intelligence. [Online] http://www.policyreview.org/feb04/russell_print.html (Accessed 20 September 2005).

Feder, S.A. 2005. Overcoming mindsets: what corporations can learn from government intelligence failures. Competitive Intelligence Review 11(3):28-36.

Fischetti, M. 2001. Drowning New Orleans. Scientific America.com. October [Online] http://www.sciam.com/article.cfm?articleID=00060286-CB58-1315-8B5883414B7F0000 (Accessed 20 September 2005).

Holtzman, J. 2005. CI blindspots. Competitive Intelligence Magazine. 8(4).

Johnson, A. 2002. Learning from intelligence mistakes. [Online]:

http://www.destinationkm.com/articles/default.asp?ArticleID=974 (Accessed 20 September 2005).

Marrs, R. and Turner, 2005. Creating an advantage through early warning signals. Intelligence Briefing. [Online] http://www.coemergence.com/news/pdf/PhotizoEarlyWarningSignals.pdf (Accessed 20 September 2005).

Newsweek. 2005. [Online] http://www.msnbc.msn.com/id/5412317/site/newsweek (Accessed 20 September 2005).

Reynolds, P. 2004. BBC Newscast, 7 November. [Online] http://news.bbc.co.uk/go/pr/fr//2/hi/middle east/3883605.stm (Accessed 20 September 2005).

UN. 2005. International strategy for disaster reduction (ISDR), January.

Wergeles, F. 2005. Developing an early warning intelligence system. Competitive Intelligence Magazine 8(3).

WSBTV. 2005. Bush, Congress promise probes of Katrina response. September. [Online] http://www.wsbtv.com/weather/4887230/detail.html (Accessed 20 September 2005).

\section{About the authors:}

Marié-Luce Muller is a consulting CI analyst with IBIS Business and Information Services (Pty) Ltd, a leading Pretoria-based CI consultancy. She has a distinguished career in CI. Her primary experience lies in assisting companies in honing their CI capabilities. She also performs tracking and scanning activities on behalf of companies. Marié-Luce has published 
many articles on competitive intelligence (CEO Magazine, Finance Week, Business Week, Beeld, Die Burger and the South African Journal of Business Management), including an article on South Africa as an emerging CI player, which was published in an international publication of the Society of Competitive Intelligence Professionals (SCIP). She has also published a series of booklets on CI (Nuts and Bolts business series, published by Knowledge Resources) and is a member of a research team participating in an international study of CI practices among exporting companies. Previously, she was involved in research into the status of CI practices in South Africa. A member of SCIP, she holds a postgraduate degree from the University of Stellenbosch.

Zenita Dürrheim is a research analyst for IBIS Business and Information Services (Pty) Ltd. With a background in psychology, Zenita has experience in competitive intelligence and research practices, having worked on numerous high profile projects in, inter alia, the petrochemical, cement, financial and property industries. Zenita obtained her post-graduate degree from the University of Stellenbosch and is registered with the Health Professions Council of South Africa (HPCSA) as a Psychometrist and Intern Psychologist. She is also a qualified Diversity Awareness Trainer and Debriefer. In addition she is qualified to conduct Targeted Selection Interviews (Deloitte \& Touche) and assess individuals through the Thomas International assessment process.

\section{Disclaimer}

Articles published in SAJIM are the opinions of the authors and do not necessarily reflect the opinion of the Editor, Board, Publisher, Webmaster or the Rand Afrikaans University. The user hereby waives any claim he/she/they may have or acquire against the publisher, its suppliers, licensees and sub licensees and indemnifies all said persons from any claims, lawsuits, proceedings, costs, special, incidental, consequential or indirect damages, including damages for loss of profits, loss of business or downtime arising out of or relating to the user's use of the Website. 
ISSN 1560-683X

Published by InterWord Communications for Department of Information and Knowledge Management, University of Johannesburg 